\title{
IS EPISTEMOLOGICAL RELIABILISM CONSISTENT WITH GRAMMATICAL EVIDENTIALITY AND CONJUNCT/DISJUNCT MARKING?
}

\author{
ELŻBIETA ŁUKASIEWICZ
}

\begin{abstract}
The paper discusses how evidentiality and conjunct/disjunct marking in grammar are related to reliabilism, a contemporary theory of epistemic justification developed within the Anglo-American analytic tradition. It is assumed that many problems and ideas concerned with theories of knowledge, and with justification of beliefs in particular, which are widely discussed in contemporary philosophical debates, are worth reconsidering in the light of what grammars of natural languages impose on the epistemic agent. Section two explains how the notions of knowledge, belief and justification are understood in the paper. The section also outlines the major problems concerning the internalist justification of beliefs. Section three presents an externalist view on the problem of justification: process reliabilism. The reliabilist theory of justification is set in the context of two grammatical categories: evidentiality and conjunct/disjunct marking (egophoricity). Since the two categories are still little known, section four offers a brief presentation of evidentiality and egophoricity in grammar, illustrated with data from two languages. Finally, section five addresses the problem whether the premises of reliabilism are reconcilable with 'natural epistemology' encoded in grammar. The final conclusion says that the externalist premises of reliabilism are certainly not congruent with grammatical evidentiality and evidentialityrelated categories, but they are not logically inconsistent therewith. Furthermore, since the reliabilist program declares interest in 'folk epistemic practices', the approach might greatly benefit from what 'natural epistemology' tells us about epistemic folk concepts and epistemic practices employed by speakers of diverse world languages.
\end{abstract}

Key words: reliabilism, epistemic justification, externalism, internalism, evidentiality, conjunct/disjunct, egophoricity, folk epistemology 


\section{Introduction: on the relation between 'natural epistemology' and philosophical epistemology}

Grammatical evidentiality and evidentiality-related categories are often defined as 'natural epistemology': 'the ways in which ordinary people, unhampered by philosophical traditions, naturally regard the source and reliability of their knowledge' (Chafe, Nichols 1986: vii). Philosophical epistemology, in turn, is conceived of as a fairly theoretical discipline; it is concerned with the nature of knowledge, theories of truth and justification, different sources of knowledge, the problem of the a priori, possible arguments against skepticism and similar academic issues. Do 'natural epistemology' and epistemology understood as the theory of knowledge have anything in common then?

If knowledge is interpreted philosophically as a body of true and well-formed beliefs, built by inference from indubitable foundations, then it might appear that 'natural epistemology' encoded in grammar or lexical resources is concerned more with common sense reasoning and opinions than with episteme in Plato's or Descartes' understanding of the term. In consequence, natural epistemology cannot contribute in any significant way to the philosophical discussion on theories of knowledge and justification. The way ordinary believers know how they know might be considered interesting in its own right but rather irrelevant to the theory of knowledge understood as episteme. However, in what follows I wish to argue that there are good reasons why 'natural epistemology' matters and the manner ordinary believers reflect on their beliefs is relevant to epistemic theory.

Foremost, a disregard for folk epistemic concepts would be self-limiting for epistemology itself. Traditionally understood, epistemology is a normative discipline whose aims include elucidating and improving the ways we form our beliefs. The ultimate goal of epistemic investigation is always getting to the truth, that is, attaining more true beliefs. If we reject the epistemic concepts of ordinary believers as naïve, uninformed and generally uninteresting for epistemology, then there is nothing to improve and the important mission of epistemology is simply lost. By claiming the due place for 'natural', or 'folk', epistemology, I do not mean that the normative concept of knowledge is to be diluted and regarded as all-inclusive. However, a normative epistemic theory which is not interested in how real people form their actual beliefs simply fails.

On the other hand, epistemology cannot be reduced to cognitive psychology, i.e. to the problem of how beliefs are actually formed or acquired. ${ }^{1}$ The key assumption of the traditional epistemology, adopted in the present paper, is that the concepts of knowledge, justification and belief are inherently normative and evaluative since they involve truth. What we ought to regard as knowledge, how we ought to form

\footnotetext{
${ }^{1}$ Cf. the project of 'epistemology naturalized' in Quine (1969); see also Kornblith (1999).
} 
our beliefs and what can be regarded as justification for them are not only legitimate, but they are also interesting epistemological questions.

This paper discusses how evidentiality and conjunct/disjunct marking in grammar are related to reliabilism, a contemporary theory of epistemic justification developed within the Anglo-American analytic tradition. I believe that many problems and ideas concerned with theories of knowledge, and with justification of beliefs in particular, are worth reconsidering in the light of what grammars of natural languages impose on the epistemic agent. When discussing reliabilist justification and setting it in the context of evidentiality and evidentiality-related category of conjunct/disjunct marking, I will obviously assume that the epistemic agent is to be construed in a generic way, not necessarily as a member of an English speaking community. This should be an implicit assumption of any epistemology if it is to be understood in a standard normative way. Epistemology is theory of knowledge regardless of the language in which that knowledge is expressed. However, many of the ideas which are prominent and widely discussed in contemporary Anglo-American epistemological debates - concerning not only reliabilism - are heavily influenced by a quite different implicit assumption, namely, that the epistemic agent speaks what we might call (after Whorf 1956) the Standard Average European language. ${ }^{2}$ Viewed from a non-Indo-European perspective, many of those ideas need to be reformulated, or should be reconsidered at least.

Do we need to care about little known and exotic languages, spoken by small groups of people, when constructing a theory of knowledge or epistemic justification? I believe we must. Otherwise, we face a rather unwelcome prospect that norms and values regarding epistemic justification of beliefs be tagged with a footnote that they pertain to speakers of some languages only, English included. It would be hard to find a normative epistemology thus limited. A viable theory of epistemic justification of beliefs must be language-neutral, which means that it must be equally defensible regardless of the language in which those beliefs are formulated. Naturally, it is not the aim of theories of epistemic justification to check whether they are resistant to diverse linguistic data, but should a given theory prove untenable in the face of available linguistic facts, it has to be reformulated. Linguistic diversity in the world is a fact, not a marginal phenomenon, and any normative epistemological theory which makes universal claims should be ready to cope with language-grounded counterarguments.

In what follows, section 2 will explain how the notions of knowledge, belief and justification are understood in the paper. The section will also outline the major problems concerning the internalist justification of beliefs. Section 3 will present an externalist view on the problem of justification: process reliabilism. The reliabilist

\footnotetext{
${ }^{2}$ See, for example, Alston (1999: 223, 228-229); this problem is discussed in more detail in Łukasiewicz (2018a: 320-329, 396-403).
} 
theory of justification will be set in the context of two grammatical categories: evidentiality and conjunct/disjunct marking (egophoricity). Since the two categories are still little known, sections 4.1 and 4.2 offer a brief presentation of evidentiality and egophoricity in grammar, illustrated with data from two languages. Finally, section 5 addresses the problem whether the premises of reliabilism are reconcilable with 'natural epistemology' encoded in grammar. The final conclusion will be that the externalist premises of reliabilism are certainly not congruent with grammatical evidentiality and evidentiality-related categories, but they are not logically inconsistent therewith. Furthermore, since reliabilism programmatically declares interest in 'folk epistemic practices', the approach might greatly benefit from what 'natural epistemology' tells us about epistemic folk concepts and epistemic practices employed by speakers of diverse world languages.

\section{Preliminaries: the notions of knowledge, belief and justification of beliefs}

The concept of knowledge has a normative character. In traditional epistemology, knowledge is regarded as a mental state that entails attaining objective truth: to know means to be in contact with facts and real states of affairs. Therefore, knowledge is not just whatever is strongly believed and supported by arguments within a given community, as some relativists claim. Nor can we reduce knowledge to a cognitive state of the mind, described in purely physicalist terms like other natural phenomena, without any ethical aspect connected therewith (as in 'epistemology naturalized'; see Quine 1969; Kornblith 1999). Knowledge is an unavoidably ethical affair.

Not only is knowledge something desirable and worth striving for, like health or good looks, but it imposes on a person a kind of moral obligation: one ought to pursue knowledge. Of course, only certain types of knowledge have that moral streak; no one would say that I am under an obligation to gather as much knowledge as possible concerning, say, my present view out the window. But if one fails to know what is important to be known and can be known, the person may be considered not only an incompetent observer, but also someone blameworthy of intellectual negligence. Since knowledge is a highly valued cognitive state which is intrinsically connected with truth, failing to know something is like a moral failure; we are obliged to be epistemically responsible and to form our beliefs the best way we can.

In traditional epistemology, knowledge has been defined as a justified true belief (JTB): to know something is to believe a proposition which is both epistemically justified and true. ${ }^{3}$ In what follows, truth will be understood as correspondence with

\footnotetext{
${ }^{3}$ In the present paper, knowledge is defined traditionally, without considering the Gettier problem (1963); for a discussion of the problems concerning the JTB theories of knowledge, see Zagzebski (1996: 283-292).
} 
mind-independent reality, as in the classical Aristotelian theory of truth. ${ }^{4}$ The terms that remain to be explained are bielief and justification.

Perhaps the most common understanding of the term belief in contemporary analytic epistemology and philosophy of language, but certainly not the only one, is that belief is a propositional attitude. ${ }^{5}$ Other propositional attitudes include desire, hope, doubt, fear, etc.; these are all mental states of having some attitude to a proposition expressed in a sentence. In the case of belief, it is an attitude of accepting a given proposition as true. It follows that thus interpreted, belief must be capable of being described in words, typically (but not necessarily) in the form: $S$ believes that $p$, where $S$ stands for a human subject (the believer) and $p$ is a proposition in the logical sense expressed in a sentence in a natural language whatever it is that is believed by $S$.

Sometimes our way of speaking about beliefs is ambiguous. By belief we mean the mental state of regarding the proposition $p$ as true, or an act of assertion whose content is $p$ or, for short, the proposition $p$ itself, as contained in the mind and represented by a sentence. These are ontologically distinct things; a mental state of accepting a proposition as true is clearly different from a proposition, or from an act of assertion, or from a sentence expressing a proposition. However, since the component of 'mental acceptance of proposition $p$ as true' is definitional for our understanding of what belief is, so whenever there may arise a similar ambiguity in the use of terms, it should not lead to any serious confusion. In what follows, belief refers to the believer's attitude to regard $p$ as true. A proposition is an object (content) of belief; it is not belief itself. The essence of this approach is that someone's belief should always have a propositional content - what is believed - which is semantically determinate and has a truth value (i.e. the proposition believed is objectively true or false, though the believer may have no cognitive access to that truth value, of course).

Believing is not an all-or-nothing affair; it comes in degrees. A typical way to represent this feature is using a scale from 0 to 1 , where 0.5 means that the subject considers the proposition as likely to be true as false, 0 indicates lack of any confidence, and 1 indicates absolute certainty. With respect to the latter, we can observe a mismatch between the use of the term belief in philosophical discourse and in casual speech. In philosophical discourse, it is appropriate to speak of beliefs when the degree of confidence in their truth value is 1 . Such indubitable beliefs based on in-

\footnotetext{
${ }^{4}$ The classical theory of truth still appears to be most resistant to critique and intuitively most appealing in comparison with its rivals: the coherentist and pragmatic theories. The literature on different theories of truth is too extensive to be cited here in any satisfactory way; for an overview see Woleński (2005), Glanzberg (2013).

${ }^{5}$ It is noteworthy that W.V.O. Quine and D. Davidson, two famous names in the analytic philosophy of language and mind, did not regard beliefs as propositional attitudes; for a discussion, see Glock (2003: 268-293).
} 
trospection or - according to some philosophers - on perception are the focus of interest for theories of epistemic justification. The matter is different in our casual use of the term belief. We can use the term when we are certain of the truth of the proposition $p$ only if it refers to our opinion (not to a fact we know), as in It is my belief that these funds must be used in a preventative manner. But it would be anomalous to use the term belief in a situation when I can be expected to have firstperson infallible knowledge on the matter, like in I believe I can see a cup on the table. This sentence would be appropriate only on condition that the degree of my belief is actually far less than 1, perhaps due to disturbances in vision, hallucinations, distance, poor light, etc. Similarly, in I believe that John is married, what I actually imply to my interlocutor is that I do not know whether the proposition expressed is true; my degree of conviction may be very high, but it is less than 1 . If I were in possession of perfectly reliable information about John's marital status, I would have used another verb, like I know that John is married, an unmarked assertion John is married or an equivalent thereof. By using I believe in this context, I indicate that my assertion is based on inference or someone's testimony, but I lack certainty - I am not in possession of the best source of evidence available to provide me with absolute certitude. In philosophical discourse, however, one can speak about infallible beliefs about which one cannot have doubts.

Of course, infallible beliefs constitute a minority in the vast body of all our beliefs. It is not unusual to hold a belief without considering its propositional content too thoroughly. Many of our everyday beliefs are of this type; we accept their content as true, sometimes we get emotionally involved, without much care about the details concerning their veracity. But such beliefs will not constitute knowledge since they lack a significant element - justification. The next issue to be explained is the problem of belief's justification.

What does it mean that a belief is epistemically justified? Does it require that the believer justify her/his belief, or is it enough that $\mathrm{s} /$ he be justified therein? In other words, does the believer need to have access to what justifies her/his belief to believe in a justified way? Is the justifier something completely internal to the mind of the cognizer; i.e. is it a mental state? What is it that may confer justification on a belief? How many of our beliefs are justified and how many are mere beliefs without a proper warrant? These are the questions which can be answered in remarkably different ways in contemporary epistemology.

What is invariable in the diverse approaches to epistemic justification is that it is inseparably connected with aiming at truth. However, a justified belief does not have to be true. When I look at my usually reliable watch, whose hands show one o'clock, I form a belief that it is one o'clock. I am justified in my belief even if my watch is out of order at the moment, and, unbeknownst to me, it is already two o'clock. My belief then is not true, but it is well-justified because in forming it, I relied on appropriate evidence available to me. 
Analogically, a true belief does not have to be justified. If I seek advice of a clairvoyant to invest my money, and I learn from that person that the company $A$ is a promising enterprise on the stock market and, accordingly, I form a belief regarding that company, my belief will not be properly justified, even if $A$ is indeed a sound investment. I cannot say that I know that the company $A$ is worth investing in. To meet requirements for being epistemically justified, a belief must be based on good evidence, the source of which is usually perception, memory, introspection, good reasoning or reliable testimony. Beliefs based on superstitions or wishful thinking cannot be the basis of knowledge, even if they happen to be true.

Justification is gradable. Our beliefs may have a very high degree of justification, for example, when my introspective awareness of pain allows me to form an indubitable belief that I feel pain in my knee, or they may be justified only well enough to hold them as reasonable beliefs, but far from certainty. One of the consequences of the premise that justification is gradable and a belief can be based on less than certain evidence is a possibility that some of our beliefs may be justified but not true, as in the above case of the broken watch. Constraints on what can provide justification (and, in consequence, which beliefs deserve to be called knowledge) have varied in different philosophical traditions. They have ranged from very rigorous Cartesian-style approaches aiming to discover what might be an indubitable basis of our reasoning to those advising rather loose requirements allowing for knowledge based on others' reports or on memory, which can be fallible. The latter usually presuppose some minimal level of justification required for a belief to be prima facie justified in the absence of recognizable defeaters.

Most of our beliefs are interconnected with other beliefs we hold in a justificatory relation; we believe that $p$ because we have a prior, apparently justified belief that $q$. Our belief that $q$, in turn, is a result of our prior belief that $x$, and so on. Now, the problem is what provides the ultimate justification in that chain of beliefs: $\ldots \rightarrow x \rightarrow q \rightarrow p$. Is that ultimate justification itself a belief or not? If it were a belief, it would not be of much help in providing justification since that belief itself would require justification and the chain might go on interminably. One should note at this point that the picture is usually more complex than our simple chain: $\ldots \rightarrow x \rightarrow q \rightarrow p$. Most of our beliefs form a multidimensional web-like structure, but for the sake of the present discussion, we can adopt that simplified scheme.

The issue of the ultimate justification in a chain of beliefs lies at the heart of what is called the epistemic regress problem. ${ }^{6}$ Generally, there are four possibilities regarding the beginning of any justificatory chain. The first is that the chain begins with a belief which simply lacks justification. But in that case, of course, any belief dependent in its justification chain on that prior unjustified belief will be unjustified

\footnotetext{
${ }^{6}$ The regress argument was formulated by Aristotle in Posterior Analytics (I.3: 72b,1-15); cf. Ziemińska (2013: 44-45).
} 
as well. In the second, the justificatory chain does not have a beginning; any belief is supported by an infinite number of other beliefs and the chain of reasoning goes on interminably. Since in this case none of our beliefs can enjoy its ultimate justification, and we must assume an infinite number of beliefs to provide justification for an even most mundane belief, this alternative is not very compelling. ${ }^{7}$ In the third option, our justificatory chain, no matter how long, is circular; it will always look as follows: $p \rightarrow \ldots \rightarrow x \rightarrow q \rightarrow p$. In consequence, a belief provides justification for itself via other beliefs. But it does not appear intuitively convincing that self-justified beliefs can be the foundation of all our knowledge.

Because these three options cannot account for the ultimate justification of our beliefs and the epistemic regress problem remains unsolved, many epistemologists have opted for a fourth alternative. They claim that since we do have justified beliefs and it would be absurd to negate this, some of our beliefs must be justified by something else but not other beliefs; i.e. they are justified non-doxastically. In epistemological foundationalism, such beliefs are called basic beliefs, or unconditionally justified foundational beliefs, because they do not derive their justification from other beliefs, at least not in any significant degree. It is true that they can be supported by other beliefs but, primarily, their source of justification lies elsewhere, because, otherwise, we would face the regress problem (see above). All other beliefs are non-basic, because their being justified depends on the justifiedness of some prior beliefs from which they are deduced.

The obvious question that arises is what may confer justification on basic beliefs. One should start with an observation that there are not too many options here. Introspection is one of such sources of justification; beliefs about my conscious mental states and sensations are unconditionally justified for me. When I have a belief that I am perceiving a cup on the table, I cannot doubt the fact that I have that belief, even if that belief is caused by hallucinations and there is actually no cup there. Analogically, my beliefs that I am in pain or that I feel sad or happy are immediately justified for me. I cannot doubt my belief that I feel happy when I am experiencing such an emotion. Beliefs about my mental states or sensations do not require correspondence with the external world; they are justified for me immediately, simply by considering those states. Mathematical and logical/analytical truths make another group of basic beliefs; for example, two plus two is four, red is not green, or all red squares are square. These beliefs are deductively inferred indubitable truths.

The view that all our justified beliefs belong to either (a) immediately justified basic beliefs, or (b) non-basic beliefs, which must derive their ultimate justification from basic beliefs (possibly through a chain of other beliefs), is to be found in all versions of epistemological foundationalism. It claims that a set of basic beliefs,

\footnotetext{
${ }^{7}$ But see Klein $(1998,1999)$, where infinitism is argued for.
} 
which are immediately and non-doxastically justified, makes the foundation of all our knowledge. ${ }^{8}$

The above view may seem an obvious solution to the epistemic regress problem. Nevertheless, some strong objections to it have been formulated, mostly, but not only, concerning the question of whether it is possible to have justification for a belief which would not involve any prior beliefs. This problem, which is the core assumption of foundationalism, has generated most of the critique, starting with the famous argument formulated by Wilfrid Sellars.

In his essay 'Empiricism and the philosophy of mind' (1963), Sellars generally criticized the concept of 'the given', and thus he also undermined the idea that nondoxastic (non-belief-like) experiential states can provide epistemic justification for beliefs. What is described as 'the given' (i.e. sensory elements of experience given immediately, without any concepts involved, e.g. the sensation of red on seeing a Ferrari car) cannot make the foundation of empirical knowledge without ascribing to it a certain truth value. However, if the truth value is required, then the concept of truth plus some other concepts and an act of judging connected therewith are intrinsically involved in our immediate sensory experience. Therefore, the idea of 'the given' is untenable. Sellars's argument was later elaborated by Laurence BonJour in The Structure of Empirical Knowledge (1985: 31), where the line of reasoning is similar in essence. Getting a non-doxastic justification for basic beliefs is an impossible task because either:

(a) some inferences are necessarily involved in the process; otherwise, there is no ground for the subject to give one of her beliefs the status of being basic, but if any inferences are involved the belief in question is no longer properly basic, or

(b) our non-doxastic experiential states are indeed exclusively qualitative and non-propositional, but then they will fail to justify anything.

Connected with the above arguments is the problem that such foundational basic beliefs, independent of other beliefs, are unthinkable. ${ }^{9}$ Let us remember that foundationalism does not deny that basic beliefs may be somehow supported by other beliefs, but they must be entirely and adequately justified by belief-independent factors. Other beliefs cannot contribute to the epistemic status of basic beliefs in any essential way, because then there looms the infinite regress problem. However, such basic beliefs, essentially independent of other beliefs, are difficult to conceive of; it would be difficult to specify what their content might be. ${ }^{10}$

\footnotetext{
${ }^{8}$ However, the different strands of foundationalism vary remarkably in their constraints on what can provide that immediate non-doxastic justification for a basic belief, or, in other words, which beliefs are basic; e.g. whether perception can provide justification for basic beliefs about the external world, as 'modest' foundationalists claim (in opposition to classical foundationalists); cf. BonJour (1999, 2003); Lemos (2007: 44-65).

${ }^{9}$ Cf. Sosa (1991 [1980], 2003).

${ }^{10}$ The implications of obligatory evidential marking for the justification of basic beliefs are analysed in Łukasiewicz (2018a, 2018b).
} 
Also, it is unlikely that there might be any real epistemic agents able and willing to pursue the task of justifying the whole content of their knowledge by deducing it from a limited number of basic beliefs. The task appears to be beyond the powers of even those who are epistemically most gifted and responsible. In consequence, the path that foundationalism offers is rather untraveled, which makes the approach even less attractive. A still bigger problem is whether it is possible in the first place to validly justify beliefs about the external world when having access to internal mental states only. Since foundationalism as a theory of justification is threatened with insoluble dilemmas, many epistemologists have turned their attention to a completely different solution, namely, an externalist source of justification, which is the topic of the next section.

\section{In search of externalist justification: the premises of process reliabilism}

Acquisition of knowledge is most often a cooperative accomplishment which involves actions by other people. Also, it depends heavily for its success on external circumstances. However, coming to know justification for one's beliefs has been traditionally understood as a solitary activity: a task an individual believer is solely responsible for. This, in turn, has always been connected with the prerequisite that in order to have a justified belief, the believer must be aware of what provides justification for that belief - be it another belief, a whole system of beliefs or some foundational experience (cf. BonJour 2003: 7).

The requirement of the accessibility of epistemic justification for the believer goes well with the concept of epistemic responsibility. The believer can be held responsible for the quality of her/his beliefs only if s/he has, or may have, conscious access to justifiers. If there are factors connected with the subject's belief which are inaccessible to her/his cognition, they cannot influence our evaluation of her/his epistemic duties, i.e. her/his believing responsibly or not. In consequence, those factors do not have any bearing on the epistemic status of the belief in question (though they may affect the belief's truth value, of course).

However, in recent decades, this well-established standpoint on the internalist nature of epistemic justification has been seriously challenged. As BonJour characterizes the retreat from epistemic internalism:

almost the only point on which large numbers of otherwise widely disparate epistemologists agree is the conviction that internalist foundationalism is an untenable, indeed hopeless, position and must be abandoned if epistemological progress is to be made. (2003: 8)

The question of whether the subject holding a justified belief needs to have a conscious access to justification (whatever the nature of the justifier: another belief, a system of beliefs or a non-doxastic experience), or that access is not necessary, 
marks the divide between epistemic internalism and epistemic externalism, which is a major dichotomy in contemporary theories of justification.

Externalists negate internalism by claiming that what provides justification for the subject's belief that $p$ may be entirely outside the scope of the subject's conscious reflection; it is enough that there is such justification. It is important to note that the externalist idea is not that the subject need not have access to everything that justifies her belief; according to externalists, the subject may hold a justified belief without a conscious access to anything that provides justification for her belief. What can justify the subject's beliefs without involving her awareness? Externalists argue that a belief may derive its justification from a good and reliable intellectual strategy employed by the subject or from her intellectual virtues. ${ }^{11}$

As a novel theory of epistemic justification, reliabilism was first presented by Alvin Goldman in his essay 'What is justified belief?' (1979). ${ }^{12}$ It has developed different outgrowths; virtue reliabilism, agent reliabilism, or some branches of social epistemology could be considered, to a greater or lesser extent, continuators of the original reliabilist theory of justification. In what follows, I will concentrate on process reliabilism as propounded by Goldman and henceforth simply referred to as reliabilism. $^{13}$

The essence of reliabilism is the claim that epistemic justification of a belief depends on how the belief was generated and how it is sustained; in other words, whether the belief in question is a product of a cognitive process which is reliable (i.e. truth-conducive).

[T] he justificational status of a belief is a function of the reliability of the process or processes that cause it, where (as a first approximation) reliability consists in the tendency of a process to produce beliefs that are true rather than false. (Goldman 2012 [1979]: 37)

To meet certain challenges (the non-sufficiency problem in particular), the above statement was later modified to the effect that 'the justificational status of a belief is not only a function of the cognitive processes actually employed in producing it; it is also a function of the processes that could and should be employed' (Goldman 2012: 46). Thus, the subject's belief is justified if it is a result of a reliable cognitive process and there are no other reliable processes 'available' to the subject which, if employed, would have changed her belief. ${ }^{14}$

${ }^{11}$ Cf. Sosa ([1980] 1991, 2003); Zagzebski (1996).

${ }^{12}$ The view was later elaborated to meet various objections and counterexamples; see Goldman (1986, 1993 [1992], 2010, 2012). In a broad sense, reliabilism may refer to any theory of knowledge (not only a theory of justification) with a special stress on the truth-conduciveness of cognitive processes and the reliability of the information-channel; cf. Dretske (1981) and Nozick (1981).

${ }^{13}$ The present account is based on Goldman's collection of essays Reliabilism and Contemporary Epistemology (2012), which includes his 1979 publication.

${ }^{14}$ However, as Goldman admits, the notion of availability is somewhat vague. There are some pending questions difficult to answer; for example, whether scientific procedures are/were available to 
Goldman enumerates some unreliable ('faulty') mental processes of belief-formation, such as confused reasoning, wishful thinking, reliance on emotional attachment, guesswork, and hasty generalization, which typically generate erroneous beliefs. Contrasted with them are some highly reliable cognitive processes based on perception, memory, good reasoning and introspection, which in most cases give rise to true beliefs (2012 [1979]: 37). Only the latter represent process types which can produce epistemically justified beliefs; the former give rise to beliefs lacking epistemic justification, though it may occasionally happen that an unreliable cognitive process will generate a true belief.

Importantly, nowhere in the above explanation is it required that the subject holding a justified belief $B$ caused by a reliable cognitive process should be aware of the reliability of the process that produced $B$. The subject does not need to have any insights or meta-beliefs about the nature and reliability of cognitive processes conferring justification on her beliefs. In order for the subject $S$ to have justified beliefs, it suffices that the processes which generated them be reliable. Thus, for example, young children may also have justified beliefs though they do not yet possess a conceptual framework to form any meta-beliefs as to the reliability of their own cognitive processes. Likewise, in our everyday life, we may have plenty of justified beliefs (i.e. produced by highly reliable mental processes), without access to the knowledge of what justifies those beliefs. Both in his 1979 and later works, Goldman is quite explicit about these externalist premises; what the believer might say in support or in defence of her belief is irrelevant to the belief's being justified.

I leave it an open question whether, when a belief is justified, the believer knows it is justified. I also leave it an open question whether, when a belief is justified, the believer can state or give a justification for it. I do not even assume that when a belief is justified there is something 'possessed' by the believer which can be called a 'justification'. I do assume that a justified belief gets its status of being justified from some processes or properties that make it justified. In short, there must be some justification-conferring processes or properties. But this does not imply that there must be an argument, or reason, or anything else, 'possessed' at the time of belief by the believer. (Goldman 2012 [1979]: 30-31)

There are many facts about a cognizer to which he lacks 'privileged access', and I regard the justificational status of his beliefs as one of those things. This is not to say that a cognizer is necessarily ignorant, at any given moment, of the justificational status of his current beliefs. It is only to deny that he necessarily has, or can get, knowledge or true belief about this status. Just as a person can know without knowing that he knows, so he can have justified belief without knowing that it is justified (or believing justifiably that it is justified). (Goldman 2012 [1979]: 42)

people living in pre-scientific cultures, or whether 'reliable available processes' should also refer to processes of collecting new evidence which might change the epistemic status of a belief (Goldman 2012: 47). 
This externalist assumption can spare reliabilism many of the aforesaid difficulties connected with internalist foundationalism. The main problems of foundationalism, namely, how an entirely sensory non-belief-like experience is to give justification to a basic belief without losing its non-doxastic character, and how relatively few basic beliefs are to provide foundation for a vast body of non-basic justified beliefs, which we ordinarily claim to have, do not arise here at all. What provides justification according to reliabilism is not a non-doxastic (sensory) experience of which the subject must be somehow aware, but a sufficiently favourable proportion of true beliefs to false beliefs generated by a given process type, which is a fact external to the subject's awareness. Another attractive feature of reliabilism is a direct and commonsensical connection between the truth and justification of beliefs - the type of processes which usually generate true beliefs will give rise to justified beliefs.

However, the very premises that allow reliabilism to avoid the foundationalist pitfalls are also the source of its main problems. First and foremost, because the believer need not be aware of what justifies her beliefs, reliabilism gives up the intuitive link between a belief's justification and epistemic responsibility of the believer. ${ }^{15}$ Furthermore, if reliability of a cognitive process is understood as the frequency of generating truth by that process type, it may happen that unsubstantiated predictions made by a clairvoyant are highly reliable. This may happen if we circumscribe the process type narrowly as 'predictions made by clairvoyant $C$ ' and refer to the truthconduciveness of thus limited process type. $C$ 's predictions, strange as it may seem, just prove to be true each time they are made. The consequence is that $C$ 's predictions should be considered perfectly reliable for any observer and, as such, they produce justified beliefs. However, since $C$ 's foretelling about the future is based on no evidence, no inferential knowledge and no acquired skills, most of us would be rather reluctant to assign $C$ 's prophecies the status of being justified. Hence, the argument has it that reliability interpreted as the frequency of generating truth by the type of a cognitive process is not sufficient for justification. ${ }^{16}$

Closely connected with such objections is the so-called generality problem: how to interpret the notion of process type to avoid too narrow or too general understanding thereof. ${ }^{17}$ It may happen that a process type is defined so narrowly that only one token of that process type ever occurs, and then the type may prove perfectly reliable (i.e. truth-conducive), even if the process type in question is intuitively

${ }^{15}$ Some epistemologists question the idea that epistemic justification requires epistemic responsibility. The argument has it that many of our beliefs, like I can feel pain in my knee or $2+2=4$, are involuntary, inescapable and beyond our control; therefore, we cannot be held responsible for them. Nevertheless, they are our best justified beliefs; for a discussion of the problem, see Lemos (2007: 111-113).

${ }^{16}$ Cf. BonJour's arguments against reliabilism (1985: 41-45); see also Feldman (1985); Foley (1985); Goldman (2012: 75, 79-80).

${ }^{17}$ For more on the generality problem, see Feldman (1985) and Conee, Feldman (1998). 
a 'faulty' mental process. The generality problem, however, as Goldman rightly notices, concerns all epistemologies of justification; it is nothing specific to reliabilism, and therefore, it should not be considered its distinctive weakness (2012: 84-85).

Some critics point to another shortcoming of reliabilism, namely, that it is hard to set standards of the degree of reliability that a process should reveal to be able to confer justification. Since processes with less than perfect reliability will also be able to generate justified beliefs, ${ }^{18}$ a measure allowing us to assess the reliability of a cognitive process should be available. There is a very general concept of 'truth-conduciveness', but it remains unclear, in Goldman's writings at least, what reliability means in practice. Goldman is aware of the problem, but he claims that a general conception of truth-conduciveness - vague as it is - meets the requirements of providing justification in normal epistemic practice. Moreover, he adds, a more precise evaluation of truth-conduciveness is in most cases simply unrealistic.

What is decidedly attractive about reliabilism is that this theory of justification is primarily interested in ordinary, common-sense beliefs concerning everyday issues. In contrast to classical foundationalists, Goldman declares that his approach is focused on ordinary standards providing justification for our everyday beliefs. Cartesian requirements of indubitable knowledge aside, the task of a normative theory of justification is to explain why some of our everyday beliefs occurring in natural situations are justified while others are not (Goldman 2012: 29). Hence, the reliabilist theory is quite appreciative of folk epistemic practices. Naïve, unsystematic and scientifically uninformed as those practices may be, epistemology should not ignore them. Goldman writes:

Whatever else epistemology might proceed to do, it should at least have its roots in the concepts and practices of the folk. If those roots are utterly rejected and abandoned, by what rights would the new discipline call itself 'epistemology' at all? (1993: 272)

The above declaration should be kept in mind when we consider below the relevance of grammatical evidentiality and egophoricity (conjunct/disjunct marking) to the externalist premises of reliabilism.

It is worth mentioning at this point that, next to folk epistemology, Goldman distinguishes also scientific epistemology, with two branches: descriptive and normative. While normative epistemology is to make epistemic judgments as to what beliefs can be considered justified (so it must be ready to depart from folk epistemic ideas), the first mission of the descriptive branch of scientific epistemology is characterizing folk epistemic practices, i.e. describing the way ordinary people use epistemic concepts and principles when they refer to the justifiedness of their beliefs. If ordinary epistemic

${ }^{18}$ Goldman writes: 'perfect reliability isn't required. Belief-forming processes that sometimes produce error still confer justification. It follows that there can be justified beliefs that are false' (2012 [1979]: 38). 
practices are to be rectified, or criticized as inadequate, they must be described first, which is a scientific task. Thus, there is continuity between folk, descriptive, and normative epistemology in Goldman's project. But even with respect to normative epistemology, what is important and really matters are regular epistemic practices.

However, the above assumption of close ties between folk epistemology and scientific epistemology, combined with the externalist premises of reliabilist justification, may prove quite problematic for the adherents of reliabilism. If we consider grammars of many natural languages, especially certain 'epistemological' categories in grammar marking the speaker's access to information (see below), it will prove that the externalist claims about the subjects' lack of epistemic awareness cannot be defended. Grammars of many languages require considerable epistemic labour from the speaker and the addressee. In the next section, the categories of evidentiality (information source marking) and egophoricity (conjunct/disjunct marking) will be introduced to show that a defender of reliabilism cannot find support for the externalist claims in the structures of natural languages and 'folk epistemic practices'.

\section{Evidentiality and egophoricity (conjunct/disjunct marking) in the grammars of natural languages}

Since the grammatical categories of evidentiality and egophoricity are still rather exotic from the Indo-European perspective, in this section some basic information about evidential and egophoric systems will be provided. The following accounts (sections 4.1 and 4.2) will be illustrated with data from two languages, Quechua ${ }^{19}$ and Newari ${ }^{20}$, where markers of the two categories are fully grammaticalized and obligatory in a sentence. Newari has both egophoricity and evidentiality in its grammar, whereas Quechua has evidentials only, without egophoric markers; the language has been chosen to exemplify evidentiality as Quechua evidentials constitute a fairly transparent system covering what is called three basic domains of evidentiality: direct, reported and inferred evidence (cf. Willett 1988: 57). An in-depth account of the subject is beyond the scope of a single paper; the two sections address the problem of evidential and conjunct/disjunct marking only to the extent it pertains to the reliabilist premises discussed in the paper.

\subsection{Evidentiality: information source marking}

Evidentiality is a category whose primary function is to mark the source of information on which a statement is based: whether the propositional content of the

\footnotetext{
${ }^{19}$ Based on Adelaar $(1977,2007)$, Weber $(1986,1989)$ and Faller $(2002)$.

${ }^{20}$ Based on Hale (1980) and Hargreaves (2005).
} 
utterance is based on the speaker's direct observation, past experience, inference from observable data, someone else's report, or other types of evidence. ${ }^{21}$ It is assumed that all natural languages have linguistic means and strategies which allow their users to express how they came to know something and what justification is available to them to support their claims. However, only some languages have fully grammaticalized evidentials ('evidentials proper'), i.e. information-source markers which constitute a specific category in grammar. In many evidential languages, such grammaticalized information-source markers are obligatory within a clause (they are most often verbal affixes), and a sentence without an evidential is deemed grammatically and semantically unacceptable. ${ }^{22}$

Grammaticalized evidentiality is not a widespread category. Given current research, it is estimated that grammatical evidentials are found in no more than one fourth of the world's languages (Aikhenvald 2004: 17; 2014: 3). They can be found on all continents; however, they are relatively infrequent in Africa and Australia, where occurrences are isolated. Also in Europe, with the exception of the Balkan Slavic and the Baltic region languages (Estonian, Latvian and Lithuanian), grammatical evidentials do not occur. In contrast, North and South American languages reveal exceptionally rich and elaborate systems of information source markers. Systems of grammatical evidentials occur also in many languages in Asia, though they are different from those in Native American languages and usually less elaborate. In particular, evidentials are found in Turkic, Caucasian and some other languages of the 'Great Evidentiality Belt' ranging from the Balkan peninsula, through Asia Minor, the Caucasus, to the central Asia and further to the Far East. Another large evidential family in Asia is the numerous group of Tibeto-Burman languages, where evidentiality is often interconnected with the marking of egophoricity (e.g. in Newari). ${ }^{23}$

Languages with grammaticalized evidentiality have different requirements as to the frequency of evidential marking; in some languages, information-source markers occur in every declarative sentence, in others, they are optional. In those languages which have obligatory evidentials, one cannot form a sentence equivalent to English: Mary is working in the garden without providing the information source in the same sentence. Therefore, the above declarative sentence will have to include in its structure an evidentiality marker, for example:

\footnotetext{
${ }^{21}$ Evidentiality was long an overlooked category in linguistics; however, in recent three decades it has become a more fashionable topic of investigation and the literature on it has grown considerably. The first monograph devoted wholly to evidentiality, Evidentiality: The Linguistic Coding of Epistemology, edited by W. Chafe \& J. Nichols, was published in 1986. For more on the topic of evidential marking, see Willett (1988); De Haan (1999, 2005); Johanson, Utas, eds. (2000); Aikhenvald, Dixon, eds. (2003, 2014); Aikhenvald (2004); Plungian (2010); see also Łukasiewicz (2014, 2018a, $2018 \mathrm{~b}$ ), where evidentiality is discussed in the context of epistemic justification of beliefs.

${ }^{22}$ Cf. Willett (1988); De Haan (1999, 2005); Aikhenvald (2003, 2004, 2014).

${ }^{23}$ Cf. Johanson, Utas, eds. (2000); Aikhenvald, Dixon, eds. (2003, 2014).
} 
Mary is working in the garden (+ direct evidential: I have seen it)

Mary is working in the garden (+ reported evidential: I have been told so)

Mary is working in the garden (+ inferred evidential: I believe so on the basis of some observable evidence)

Giving the source of information whenever one makes an assertion is a prerequisite of successful communication in evidential languages. Moreover, evidentiality is often fused with other grammatical categories (e.g., tense, person) in portmanteau morphs; therefore, omission of evidentials is inconceivable from the viewpoint of sentence structure and would produce grammatically unacceptable and semantically flawed sentences.

Evidentials may develop various semantic extensions, for example epistemic or mirative overtones. Then, apart from the primary job of pointing to the information source, they also indicate, or imply, a degree of reliability of the information provided (epistemic extension) or its novelty and unexpectedness (mirativity). For example, a sentence with the reported evidential, equivalent to English: Mary has moved to London (+ reported evidential: I have been told so) will imply that the information is not as reliable as it would have been if the visual marker had been included. ${ }^{24}$

Languages with grammatical evidentiality vary widely in how large their evidential systems are, that is, how many information sources they specify and mark in grammar, whether all information sources are overtly marked, and whether a given system allows for evidentially neutral statements or not. There are languages with small systems, where only one type of information source is formally marked with an evidential, while other information sources go unmarked. For example, only the reported, or, in other languages, the non-firsthand evidence will be marked, and thus opposed to unmarked 'others'. In contrast, there are languages with systems consisting of as many as five (or more) evidentials for different information sources, all formally marked, where an evidential marker is obligatory in a clause - there are no evidentially neutral assertions in such languages. ${ }^{25}$

To illustrate in brief how grammatical evidentiality works, examples from Quechua will be quoted. ${ }^{26}$ Evidentials in this language (suffixes $-m i,-s i$ and $-c h a ́$ )

${ }^{24}$ The relation between the categories of evidentiality and epistemic modality is a controversial issue, which is much discussed in the growing evidential literature, next to the problem of the strictly grammatical nature of evidentials; for different views on the topic, see Chafe (1986), Willett (1988), De Haan (1999), Aikhenvald (2004), Plungian (2010); an overview of the problem is provided in Łukasiewicz (2018a: 119-136).

${ }^{25}$ For example, in Tariana (Aikhenvald 2003) and Tuyuca (Barnes 1984), both spoken on the border between Brazil and Colombia, which have five-option systems.

${ }^{26}$ Quechua (8.5-10 million speakers, mainly in Peru, Bolivia, Ecuador, north Chile and Argentina) has several different dialects, or Quechua languages, as some linguists prefer to call them; cf. Adelaar (2007: 168). The following varieties of Quechua are most frequently quoted in the literature on evidentiality: Tarma Quechua (Adelaar 1977, 2007), Huallaga (Huánuco) Quechua (Weber 1986, 1989), and Cuzco Quechua (Faller 2002); the present account is based on these works. 
cover what is called three basic domains of evidentiality: direct, reported and inferred evidence. Quechua evidential markers are not fused with markers of other categories; they constitute a system of independent suffixes/enclitics which occupy their slot in a sentence regardless of other grammatical suffixes (e.g. markers of tense or aspect). These evidential suffixes can be agglutinated to any syntactic category, not necessarily to a verb; they are typically attached last to the first available syntactic element of a sentence (Adelaar 2007: 209). The Quechua evidentiality system can be exemplified with three simple sentences from Cuzco Quechua (Faller 2002: 3$)$, as in $(1 . \mathrm{a}-\mathrm{c})$.

(1) Cuzco Quechua (Faller 2002: 3)

(a)

Para-sha-n-mi

rain-PROGRESSIVE-3.PERSON-DIRECT

'It is raining' (the speaker sees that $p$ )

(b)

Para-sha-n-si

rain-PROGRESSIVE-3.PERSON-REPORTED

'It is raining' (the speaker was told that $p$ )

(c)

Para-sha-n-chá

Rain-PROGRESSIVE-3.PERSON-CONJECTURE

'It might/must be raining' (the speaker conjectures that $p$ )

The suffix - $m i$ (allomorphs: $-m i,-n,-m$ ) means 'learned by direct experience'; -si (allomorphs: $-s i,-s h i,-s,-s h$ ) encodes 'learned indirectly, from someone's report, secondhand, hearsay'; and -chá (allomorphs: -chá, -chi, -ch) indicates 'conjecture based on the speaker's reasoning' (Weber 1986: 139-140; 1989: 419-439; Adelaar 2007: 210-211). Significantly, evidentiality in a Quechua sentence may be formally unmarked; if a declarative sentence does not have any of the three suffixes, it is interpreted as covertly marked for direct experience (Faller 2002: 14).

As in many other evidentiality systems, Quechua evidentials may also, in certain contexts, indicate the speaker's attitude to the veracity of the statement. This epistemic extension considerably overlaps with their evidential function; interestingly, Quechua evidentials have been regarded as validationals by some researchers. For example, in his analysis of Tarma Quechua (1977: 79), Adelaar claims that the three suffixes 'indicate the validity of the information supplied by the speaker'; in (2007: 210), he calls the three suffixes validators, translating them into English as 'I know', 'I heard', and 'I guess', respectively. ${ }^{27}$

\footnotetext{
${ }^{27}$ The problem of diverse interpretations of Quechua evidentials is discussed in more detail in Łukasiewicz (2018a: 423-437).
} 
In evidential languages, like Quechua, one has to be precise about one's information source. Obviously, it is possible to lie and provide a false source of information, but the marker of information source must be included in a clause. Speakers of languages whose grammars have obligatory evidentiality may find utterances in other languages (i.e. without obligatory evidential markers, like English) imprecise and inadequate in semantic content. The linguists who describe evidentiality systems, e.g. in native American languages, often point to the speakers' remarkable metalinguistic awareness of how important it is to provide the information source (cf. Aikhenvald 2004: 9-10).

Summing up, those who speak languages with obligatory grammatical evidentiality cannot omit evidential markers in their utterances; they must be precise about where the information comes from. It is unavoidable for both grammatical and socio-pragmatic reasons; evidentials are regarded as essential for adequate communication. Also, they are highly valued meta-textual expressions, and trustworthy speakers are expected to use them properly. Their primary function is to mark the source of information; however, in many languages grammaticalized evidentials develop epistemic extensions, and, apart from the source, they indicate the reliability of the evidence on which a statement is based.

\subsection{Egophoricity: conjunct/disjunct marking}

What is egophoricity, or, in other words, conjunct/disjunct opposition? To put it in a simple way, egophoricity depends on a binary morphological marking - usually on verbs - that distinguishes first person actor (egophoric/conjunct) from second and third person actors (non-egophoric/disjunct) in declarative clauses, and second person (egophoric/conjunct) from first and third persons (non-egophoric/disjunct) in questions. From the perspective of speech act roles, the egophoric/conjunct marks the person who makes an assertion based on internal experiential knowledge, i.e. the speaker-actor in first person statements, or the person who is able to make such an assertion when answering a question, i.e. the second person addressee in questions.

Cross-linguistically, the occurrence of conjunct/disjunct marking is not widespread. It can be found in some languages of the Tibeto-Burman family, although not in all branches; also, it has been described in several Northeast Caucasian languages, ${ }^{28}$ and in the Barbacoan family ${ }^{29}$ in Colombia and Ecuador. A system of egophoric marking was first analysed by Austin Hale in his groundbreaking article (1980) on conjunct and disjunct verb forms in Newari (Newar), a Tibeto-Burman language of Nepal. In order to label that binary distinction, Hale used the terms conjunct/disjunct; in this he was followed by many other researchers (to the motivation for this terminology we will return).

\footnotetext{
${ }^{28}$ For example, in Akhvakh (Creissels 2008) and Dargwa (Magometov 1982).

${ }^{29}$ For example, in Awa Pit (Curnow 2002) and Tsafiki (Dickinson 2000).
} 
To illustrate briefly how the system of egophoric (conjunct/disjunct) marking works, I will quote a simple example from Newari, as presented in Hale's (1980) and Hargreaves's (2005) accounts. The Newari verb wane ('to go') has a conjunct and a disjunct form in the past tense paradigm; consider (2.a-c) below.

(2) Newari conjunct/disjunct paradigm (egophoric/non-egophoric) in past tense declaratives; based on Hale (1980: 95) and Hargreaves (2005: 12)

(a)

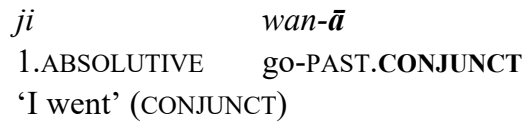

(b)

cha wan-a

2.ABSOLUTIVE go-PAST.DISJUNCT

'You went' (DISJUNCT)

(c)

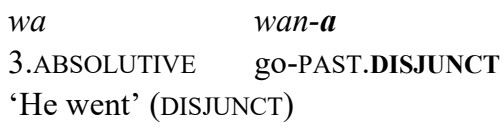

The same opposition exists in the non-past. It is important not to interpret the conjunct/disjunct distinction as merely first vs. non-first person marking on verbs, as the above pattern might suggest. While the disjunct form is used in second person declaratives, in second person questions, the conjunct will be used, as in (3) below.

(3) Newari conjunct (egophoric) in 2nd person question; based on Hale (1980: 95) and Hargreaves (2005: 15-16)

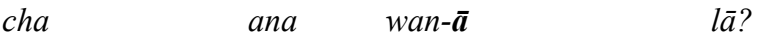

2.ABSOLUTIVE there go-PAST.CONJUNCT QUESTION

'Did you go there?' (CONJUNCT)

Furthermore, though in third person simple declaratives and in third person questions we have disjunct forms only, in certain embedded clauses, it is the conjunct that is the appropriate third person form and will be chosen, as in (4.a). If the disjunct form is used in the same context, the meaning changes significantly; see (4.b) below.

(4) Newari (Hale 1980: 95)

(a)

Wã: wa ana wanā $\overline{\boldsymbol{~}}_{\text {(go-PAST.CONJUNCT) }}$ dhakāā dhāla

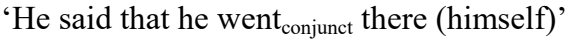

(b)

Wã: wa ana wana (go-PAST.DISJUNCT) $_{\text {dha }}$ ẫa dhāla

'He said that he (someone else) went disjunct $_{\text {there' }}$ 
What is significant, the conjunct/disjunct (egophoric/non-egophoric) pattern is used with only some of Newari verbs - the so-called 'personal' verbs, to use Hale's terminology. These are verbs whose subject-actor 'is portrayed as a true instigator, one responsible for an intentional act' (1980: 96); only personal verbs may have conjunct forms. Hargreaves (2005: 4, 22-30) calls this group of Newari verbs 'control verbs', which highlights the subject's intention to act and her control over the action described by the verb. This aspect distinguishes 'control' verbs from 'noncontrol' verbs ('impersonal' in Hale 1980), which make a much larger class, 'describe events incompatible with self-initiated behavior', and have disjunct forms only, regardless of person (Hale 1980: 96; Hargreaves 2005: 13-14). Apart from these two classes, a third is distinguished in Hargreaves (2005), the so-called 'fluid' verbs, which allow for both interpretations concerning volition and control on the subject's part. Therefore, fluid verbs occur in either conjunct/disjunct or disjunctonly forms. The importance of the control component is visible in pairs of utterances like $(5 . \mathrm{a}-\mathrm{b})$ below, in which the use of a conjunct or disjunct form with a fluid verb indicates where the actor is a true instigator.

(5) Newari, intentional and non-intentional interpretations encoded by the conjunct/disjunct opposition (egophoric/non-egophoric); based on Hargreaves (2005: 14)

(a)

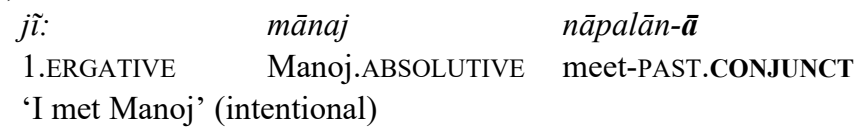

(b)
$j \tilde{i}:$
mānaj
nāpalān-a
1.ERGATIVE Manoj.ABSOLUTIVE meet- PAST.DISJUNCT
'I met/ran into Manoj' (non-intentional)

The above examples show clearly that the egophoric, or the conjunct, is not simply a person marker (i.e. of first person in statements and second person in questions). What governs the distribution of conjunct/disjunct forms is an interaction of pragmatic, semantic and morphosyntactic factors. The following two questions are essential in applying the conjunct form in Newari. Firstly, does the event described by the verb involve an intentional act? Only those verbs whose meaning entails the actor's intention to act and her control have conjunct forms; non-control (impersonal) verbs are always disjunct. The second question is more general and applies to egophoricity systems in other languages as well; it concerns the epistemic authority for the proposition asserted: who has a privileged access to internal experiential knowledge concerning the truth of the proposition? In declarative clauses, it is the speaker (first person), and therefore, the conjunct form is used.

Regarding the use of conjunct/disjunct forms in questions, the conjunct is used in second person questions (with personal/control verbs) of the type Did you go 
there? It is the addressee who is the 'primary knower' and will be marked as the person able to make an assertion based on internal experiential knowledge; therefore, the conjunct is employed. One could say that the form used in the question anticipates the form provided in the answer.

In the case of questions cast in first person and rhetorical questions, the distribution of the conjunct is different (Hale 1980: 99-100). The speaker who does not remember her own actions (provided the question in first person is a true question) or did something unwittingly cannot be treated as a true instigator who is in control of her activity. Therefore, in 'true' first person questions (e.g. Did I go there at that time (I don't recall)?) the disjunct form is used. The situation is different in rhetorical questions. They may have various pragmatic functions: emphasis, denial, accusation, etc., but the addressee is not the 'primary knower' and is not asked for any information. Since rhetorical questions are not true questions, the declarative pattern is used there, i.e. the conjunct in first person and the disjunct in second person (Hale 1980: 99-100); see (6.a-b) below.

(6) Newari reversed conjunct/disjunct marking (egophoric/non-egophoric) in first and second person rhetorical questions; Hale (1980: 100)

(a)

$\begin{array}{llll}j i & \text { ana } & \text { wan }-\bar{a} & l \bar{a} ? \\ \text { 1.ABSOLUTIVE } & \text { there } & \text { go-PAST.CONJUNCT } & \text { QUESTION } \\ \text { 'Did I go there? (I most certainly did not!)' (CONJUNCT) } & \end{array}$

(b)

$\begin{array}{lll}\text { cha } & \text { wal- } \boldsymbol{a} & l \bar{a} ? \\ \text { 2.ABSOLUTIVE } & \text { come-PAST.DISJUNCT } & \text { QUESTION } \\ \text { 'Did you come? } & \text { (Most certainly not!)' (DISJUNCT) }\end{array}$

Since Hale's 1980 publication on Newari verb forms, various other terms have been used to name systems of such binary marking in different languages: first/nonfirst person (Woodbury 1986), selflother person (Sun 1993), congruent/noncongruent (Dickinson 1999), assertor's involvement marking (Creissels 2008), egophoric/neutral (alterphoric) (Tournadre 2008; Post 2013). The terms egophoric/nonegophoric seem to be semantically more transparent than conjunct/disjunct, and they highlight the role of ego as the epistemic authority for the utterance. Hale's terminology (1980) was originally prompted by the occurrence of two different verb forms in complement clauses of verbs of saying - depending on the co-reference of the subject of the main clause and the subject of the complement clause, or lack of such co-reference, as illustrated by the pattern below:

\begin{tabular}{l|l}
\hline CONJUNCT: & $\boldsymbol{H e}_{\boldsymbol{x}}$ said that $\boldsymbol{h e}_{\boldsymbol{x}}$ went $_{\text {conjunct }}$ there \\
\hline DISJUNCT: & $\boldsymbol{H} \boldsymbol{e}_{\boldsymbol{x}}$ said that $\boldsymbol{h e}_{\boldsymbol{y}}$ went $_{\text {disiunct }}$ there \\
\hline
\end{tabular}

In order to account for the use of conjunct/disjunct forms in unembedded clauses (i.e. in simple declaratives) and create a unified account of the phenomenon, Hale 
advocated treating such unembedded clauses as 'quotes' in an abstract 'quote frame', understood as an implicit main clause of the type: I say to you (1980: 97). The quote frame has an implicit performative verb with the speaker as the implicit subject (see below). This can explain the use of conjunct forms in first person unembedded declarative sentences analogically to their use in embedded clauses; the conjunct form is used only if the subject of the 'quote' is co-referential with the subject of the implicit 'quote frame' (i.e. with the speaker), as below.

\begin{tabular}{|c|c|}
\hline QUOTE FRAME & QUOTE (a declarative sentence) \\
\hline [I say to you $]$ & I went $_{\text {conjunct }}$ there. \\
\hline
\end{tabular}

Further studies oln egophoricity in other languages ${ }^{30}$ have shown that the picture can be more complex than in the Newari system. The main organizational principle is generally the same, but there are differences revealed in: the semantic type of verbs which are marked for egophoricity; the interactions of the egophoric with other categories like tense, aspect, mood, evidentiality, or mirativity; the morphological type of markers; the argument role of the egophoric person (i.e. whether it is limited to a conjunct grammatical subject or more loosely defined); possible subdivisions in the conjunct (active and passive participation); and occurrence of the conjunct/disjunct markers with syntactic elements other than finite verbs.

Taking into account the differences in egophoric systems, a broader view might look as follows. The conjunct (egophoric) form is used in statements when the speaker is involved in the activity described by the verb, and in questions when the addressee is thus involved; it marks the person who is the epistemic authority to express a given proposition. The disjunct (non-egophoric) form is used in all other cases, i.e. in statements or in questions where the speaker or the addressee, respectively, are not involved in the activity referred to by the verb.

One could ask at this point about the relations between the two categories; whether egophoricity and evidentiality are, cross-linguistically, distinct categories, or perhaps the conjunct/disjunct marking might be regarded as part of evidentiality. What makes egophoricity markers similar to evidentials is the key role of the criterion of access to (in)direct knowledge, but this criterion is used in a different way. While evidentials mark the source of information for the statement from the point of view of the speaker (be it any direct or indirect source), egophoricity marks whether the person who has access to direct, first-person knowledge regarding the truth of the information is or is not present in the utterance. Therefore, these two categories are semantically related, but their focal points are different. ${ }^{31}$

\footnotetext{
${ }^{30}$ Cf. Dickinson (2000); Curnow (2002); Creissels (2008); Post (2013).

${ }^{31}$ For more on the relations between the two categories, see Łukasiewicz (2018a: 136-150).
} 


\section{Conclusion: externalist premises of reliabilism in the context of 'natural epistemology'}

How does the reliabilist theory of justification relate to grammatical categories like evidentiality and conjunct/disjunct marking? The first impression could be that the externalist assumptions of reliabilism are irreconcilable with obligatory marking of the source of information (evidentials) and epistemic authority for the proposition expressed (egophoricity). The characteristic feature of these linguistic categories is marking how the speaker got the information on which the assertion is based or who is 'the primary knower'. Therefore, a degree of conscious access to what justifies the assertion is taken for granted; otherwise, evidential or conjunct/disjunct marking would not be possible. Reliabilism, as explained in section 3, does not require that the cognizer have access to the justificational status of her beliefs. Goldman is quite explicit that it is not necessary:

[J]ust as a person can know without knowing that he knows, so he can have justified belief without knowing that it is justified (or believing justifiably that it is justified). (2012 [1979]: 42)

However, even though reliabilism does not require an internal access to justification, it is obviously possible that the cognizer may have an epistemic awareness of the status of her/his belief; i.e. s/he may be aware that this or that belief has been generated by one of truth-conducive mental processes, for example by perception, and it is therefore justified. But significantly, this does not bear upon the fact that what justifies the belief is the truth-conduciveness of the belief-forming process; the belief is justified by this external fact - with or without the believer's awareness of it. Thus, one could say that in languages in which one has to mark the source of information or egophoricity in every clause, the speaker's epistemic awareness is simply switched on. In other languages, it may be off, but the reliabilist justification operates regardless of such facts. It must be stressed that externalism negates the necessity of the believer's access to justification, not the possibility thereof. Therefore, the externalist premises of reliabilism do not seem in any obvious way logically inconsistent with obligatory evidentials and egophoric (conjunct/disjunct) marking. Though, certainly, they are not in the spirit of 'natural epistemology' but merely logically consistent therewith.

What is significant, other postulates of the reliabilist theory, as noted in section 3 , declare much interest in folk epistemic practices. One of Goldman's papers is particularly noteworthy with regard to linguistic evidentiality and conjunct/disjunct marking. In 'Epistemic folkways and scientific epistemology' (1993 [1992]), a theory is proposed which describes how ordinary people assign justifiedness to their everyday beliefs. It may be interesting to consider how this theory, focused specifically on common-sense epistemic concepts and norms, could be supported, or even 
enriched, if linguistic evidentiality were taken into account. Importantly, it is a descriptive theory, not a normative one, so it does not answer the question of what makes a given belief justified, but it offers an account of 'epistemic folkways' - how ordinary people assess their beliefs as justified or not.

According to the theory, we have a mental store of 'good' and 'bad' ways of forming beliefs, which Goldman labels respectively epistemic 'virtues' and 'vices'. ${ }^{32}$ That store of epistemic virtues and vices in the mind consists of mental representtations of positive and negative epistemic 'exemplars' of belief-forming processes. These are exemplars in the sense propounded by the psychology of concepts rather than abstract definitions and principles. When the subject is to judge whether a particular belief is justified, s/he simply tries to match the relevant belief-forming process to those positive and negative 'exemplars' stored in her/his mind (Goldman 1993: 274-277).

Now, assuming that indeed we refer to such 'exemplars' stored in the mind when making epistemic judgments, there remains the question of how we acquire such lists of virtues and vices. It is obvious that the relevant exemplars are selected ultimately on the basis of their reliability, but it is an interesting problem to what extent the lists of virtues and vices are individualized; they are formed, stored and made use of in individual minds after all. Goldman writes that the epistemic agent need not apply the reliability tests her-/himself when selecting the norms; instead, the list of epistemic virtues and vices may be inherited, at least partly, from her/his linguistic community. This does not imply that all speakers will have the same list; individual differences are permitted, but on the whole, speakers will be guided by a preference for epistemic conservatism and will not be willing to revise socially accepted norms.

When considering the question of what supports the view that ordinary believers indeed have such mental lists of reliable and unreliable epistemic practices, Goldman points to the acceptability of some utterances in ordinary language. That we have a mental store of intellectual virtues and vices is shown by the evidential strategies we employ when explaining how we came to know something; some sources of information are acceptable as the basis of knowledge, others are not. Since our everyday utterances are not anomalous, it is clear that we have some fixed ideas of which sources of information are reliable (cf. Goldman 1993: 282).

Though Goldman does not mention linguistic evidentiality, it is tempting to set the above theory in evidentiality framework, of course. One could say that in many languages grammatical markers of information source (with their semantic extensions of veracity or unreliability, e.g. visual vs. reported markers), constitute explicit, not only mental, lists of more and less reliable epistemic practices, which are inhe-

\footnotetext{
${ }^{32}$ In adopting this terminology, Goldman explicitly refers to Ernest Sosa's writings and virtue epistemology.
} 
rited from the linguistic community and shared within. The fact that visual evidentials are always preferable if the sources of information are many ${ }^{33}$ proves that visual perception is at the top of the list of epistemic 'virtues'. Undoubtedly, Goldman is right to refer to evidential strategies in language, but he definitely underestimates the scope and richness of folk epistemology; hence, he reduces the mission of descriptive epistemology. He writes:

It is quite possible that the folk do not have highly principled methods for individuating cognitive processes, for 'slicing up' virtues and vices. If that is right, it is a mistake to insist that descriptive epistemology uncover such methods. It is no flaw in reliabilism, considered as descriptive epistemology, that it fails to unearth them. (Goldman 1993: 281282)

In the above passage, Goldman refers to the generality problem in reliabilism (i.e. how to define the process type, see above), and he suggests that folk epistemology is similarly vague and unsystematic as far as this problem is concerned. Therefore, reliabilism is not particularly blameworthy if it does not offer a precise and systematic account of the types of reliable cognitive processes in beliefformation. ${ }^{34}$ The aim of the present paper has been to show that 'epistemic folkways' are much more elaborate and sophisticated than some contemporary theories of justification assume. The folk methods for individuating cognitive processes are not only 'highly principled', since they are encoded in a systematic way by special grammatical categories, but they are also extremely variegated in the world's languages. The existence of 'epistemological' categories in grammar, like evidentiality, egophoricity (conjunct/disjunct marking), epistemic modality, or mirativity, to mention some only, proves that the epistemic awareness of the folk and the processing of epistemic information are constantly switched on; otherwise, these categories could not be properly used by the speakers. If we agree with Goldman that the first mission of scientific epistemology is describing epistemic concepts and principles of the folk, then the task should obviously include taking account of evidentiality, egophoricity and other 'epistemological' categories in language.

The interest of the present paper has concentrated on the concept of justification as it is used in the mainstream of contemporary analytic epistemology. In this tradition, the epistemic agents are individuals. The paper has not discussed the various new extensions of traditional epistemology, often labeled 'social epistemologies', which concentrate on either collective epistemic agents, such as committees, juries, courts, etc., or social epistemic systems. However, it is clear that particularly the latter (i.e. systems-oriented social epistemology) might benefit from studying the

\footnotetext{
${ }^{33}$ The hierarchy in evidentiality systems is discussed in Łukasiewicz (2018a: 82-90).

${ }^{34}$ See also Goldman's essay 'Epistemic relativism and reasonable disagreement' (2012: 207), where he writes: 'comparatively few individuals form explicit beliefs about the justificational status of their own (first-order) attitudes. Only fairly reflective minds contemplate this sort of thing.'
} 
interface of broadly understood linguistic evidentiality (grammatically and lexically encoded), communication and social epistemic practices. ${ }^{35}$ Systems-oriented epistemology, as defined by Goldman (2012: 228-229), is focused on how different social institutions, procedures and patterns of interpersonal contact in a community influence the epistemic situation of its members. Generally, the mission of epistemic systems, both formal (science, journalism, education, etc.) and informal (ordinary information-exchange patterns), is to elevate the community's level of knowledge possession and rationality of beliefs. It goes without saying that communication and language in general, but in particular information-source marking and other evidentiality-related categories, constitute vitally important social communicative procedures affecting beliefs, epistemic attitudes and judgments of community members. The workings of formal and informal social epistemic systems, duly enriched with linguistic aspects, should be viewed as part of a broadly understood ecocommunicative network, in which human epistemic agents, by participating in the universal communication space and employing various linguistic and non-linguistic resources available there, "contribute jointly to the generation of a global sense of communicative assonance and [epistemic] well-being' (Puppel 2017: 71; bracketed addition EŁ).

\section{References}

Adelaar, W.F.H. 1977. Tarma Quechua: grammar, text, dictionary. Lisse: Peter de Ridder Press.

Adelaar, W.F.H. (with the collaboration of P.C. Muysken). 2007. The languages of the Andes. Cambridge: Cambridge University Press.

Aikhenvald, A.Y. 2003. "Evidentiality in Tariana". In: Aikhenvald, A.Y. and R.M.W. Dixon. (eds.). Studies in evidentiality. Amsterdam, Philadelphia: John Benjamins Publishing Company. 131-164.

Aikhenvald, A.Y. 2004. Evidentiality. Oxford: Oxford University Press.

Aikhenvald, A.Y. 2014. "The grammar of knowledge: a cross-linguistic view of evidentials and the expression of information source". In: Aikhenvald, A.Y. and R.M.W. Dixon. (eds.). The grammar of knowledge. A cross-linguistic typology. Oxford: Oxford University Press. 1-51.

Aikhenvald, A.Y. and R.M.W. Dixon. (eds.). 2003. Studies in evidentiality. Amsterdam, Philadelphia: John Benjamins Publishing Company.

Aikhenvald, A.Y. and R.M.W. Dixon. (eds.). 2014. The grammar of knowledge. A cross-linguistic typology. Oxford: Oxford University Press.

Alston, W. 1999. "Perceptual knowledge". In: Greco, J. and E. Sosa. (eds.). The Blackwell guide to epistemology. Malden, Mass.: Blackwell Publishing. 223-242.

Aristotle. 2015 [350 BC]. Posterior Analytics. Translated by G.R.G. Mure. Accessed August 2015. https://ebooks.adelaide.edu.au/a/aristotle/a8poa/book1.html

\footnotetext{
${ }^{35}$ For a comprehensive account of 'social epistemologies', see Goldman (2012: chapters 9-10). It is essential that social epistemologies be considered also within the framework of ecolinguistics, with due focus on the role and use of the resources of natural languages in highly diversified acts of human communication contributing to the spread of knowledge; for an overview of the ecolinguistic approach, see Puppel (2017); also: Haugen (1972).
} 
Barnes, J. 1984. "Evidentials in the Tuyuca verb". International Journal of American Linguistics 50. 255-271.

BonJour, L. 1985. The structure of empirical knowledge. Cambridge, Mass.: Harvard University Press.

BonJour, L. 1999. "The dialectic of foundationalism and coherentism". In: Greco, J. and E. Sosa. (eds.). The Blackwell guide to epistemology. Malden, MA.: Blackwell. 117-142.

BonJour, L. 2003. "A version of internalist foundationalism". In: BonJour, L. and E. Sosa. Epistemic justification: Internalism vs. externalism, foundations vs. virtues. Malden, Mass.: Blackwell. 3-96.

Chafe, W. 1986. "Evidentiality in English conversation and academic writing". In: Chafe, W. and J. Nichols. (eds.). Evidentiality: The linguistic coding of epistemology. Norwood, N.J.: Ablex Publishing Corporation. 261-272.

Chafe, W. and Nichols, J. (eds.). 1986. Evidentiality: The linguistic coding of epistemology. Norwood, NJ: Ablex Publishing Corporation.

Conee, E. and Feldman, R. 1998. "The generality problem for reliabilism". Philosophical Studies 89. $1-29$.

Creissels, D. 2008. "Remarks on so-called 'conjunct/disjunct' systems" In: Syntax of the World's Languages III. Berlin. Accessed June 2014. http://www.deniscreissels.fr/public/Creissels-conj.disj.pdf

Curnow, T.J. 2002. "Conjunct/disjunct marking in Awa Pit". Linguistics 40.3. 611-627.

De Haan, F. 1999. "Evidentiality and epistemic modality: Setting boundaries". Southwest Journal of Linguistics 18.1. 83-101.

De Haan, F. 2005. "Encoding speaker perspective: Evidentials" In: Frajzyngier, Z. and A. Hodges and D.S. Rood. (eds.). Linguistic diversity and language theories. Amsterdam: John Benjamins Publishing Company. 379-397.

Dickinson, C. 1999. "Semantic and pragmatic dimensions of Tsafiki evidential and mirative markers". Chicago Linguistic Society 35 (The Panels). 29-44.

Dickinson, C. 2000. "Mirativity in Tsafiki”. Studies in Language 24.2. 379-421.

Dretske, F. 1981. Knowledge and the Flow of Information. Cambridge, Mass.: MIT Press.

Faller, M. 2002. "Semantics and Pragmatics of Evidentials in Cuzco Quechua”. PhD Dissertation. Stanford University. Accessed June 2016. http://personalpages.manchester.ac.uk/staff/martina.t.faller/ documents/Thesis.pdf

Feldman, R. 1985. "Reliability and justification". Monist 68. 159-174.

Foley, R. 1985. "What's wrong with reliabilism?". Monist 68. 188-202.

Gettier, E. 1963. "Is justified true belief knowledge?". Analysis 23. 121-123.

Glanzberg, M. 2013. "Truth". In: The Stanford Encyclopedia of Philosophy. Accessed October 2015. https://plato.stanford.edu/entries/truth/

Glock, H.J. 2003. Quine and Davidson on language, thought and reality. Cambridge: Cambridge University Press.

Goldman, A.I. 1986. Epistemology and cognition. Cambridge, Mass.: Harvard University Press.

Goldman, A.I. 1993 [1992]. "Epistemic folkways and scientific epistemology". Philosophical Issues 3. Science and Knowledge. 271-285.

Goldman, A.I. 2010. "Systems oriented social epistemology". In: Gendler, T.S. and J. Hawthorne. (eds.). Oxford studies in epistemology 3. Oxford/New York: Oxford University Press.

Goldman, A.I. 2012 [1979]. "What is justified belief?" In: Goldman, A.I. Reliabilism and contemporary epistemology. Oxford: Oxford University Press. 29-49.

Goldman, A.I. 2012. Reliabilism and contemporary epistemology. Oxford: Oxford University Press.

Hale, A. 1980. "Person markers: finite conjunct and disjunct verb forms in Newari". In: Trail, R. (ed.). Papers in Southeast Asian Linguistics 7. Canberra: Pacific Linguistics. 95-106.

Hargreaves, D. 2005. "Agency and intentional action in Kathmandu Newar”. Himalayan Linguistics 5. $1-48$. 
Haugen, E. 1972. The ecology of language. Stanford: Stanford University Press.

Johanson, L. and B. Utas. (eds.). 2000. Evidentials: Turkic, Iranian and neighbouring languages. Berlin: Mouton de Gruyter.

Klein, P. 1998. "Foundationalism and the infinite regress of reasons". Philosophy and Phenomenological Research LVIII. 919-926.

Klein, P. 1999. "Human knowledge and the regress of reasons". Philosophical Perspectives 13. 297-325.

Kornblith, H. 1999. "In defense of a naturalized epistemology". In: Greco, J. and E. Sosa. (eds.) The Blackwell guide to epistemology. Malden, Mass.: Blackwell. 158-169.

Lemos, N. 2007. An introduction to the theory of knowledge. Cambridge: Cambridge University Press.

Łukasiewicz, E. 2014. "Obligatoryjne określniki źródła wiedzy w językach naturalnych i ich epistemologiczne konsekwencje”. Filozofia Nauki XXII 2.86. 97-115.

Łukasiewicz, E. 2018a. Linguistic evidentiality and epistemic justification of beliefs. Bydgoszcz: Wydawnictwo Uniwersytetu Kazimierza Wielkiego.

Łukasiewicz, E. 2018b. "The concept of basic beliefs and obligatory grammatical evidentiality: an evidentiality-based argument against foundationalism". Archiwum Historii Filozofii i Myśli Spotecznej Vol. 63/2018. 159-186.

Magometov, A. 1982. Megebskij dialekt darginskogo jazyka (The Mehweb dialect of the Dargwa Language). Tbilisi: Mecniereba.

Moser, P.K. 1999. "Belief”. In: Audi, R. (ed.). The Cambridge Dictionary of Philosophy. Second Edition. Cambridge: Cambridge University Press. 78-79.

Nozick, R. 1981. Philosophical Explanations. Cambridge, Mass.: Harvard University Press.

Plungian V.A. 2010. "Types of verbal evidentiality marking: an overview". In: Diewald, G. and E. Smirnova. (eds.). Linguistic realization of evidentiality in European languages. Berlin: Mouton de Gruyter. 15-58.

Post, M.W. 2013. "Person-sensitive TAME marking in Galo". In: Thornes, T., Andvik, E., Hyslop, $\mathrm{G}$ and J. Jansen. (eds.). Functional-historical approaches to explanation. Amsterdam: John Benjamins Publishing Company. 107-130.

Puppel, S. 2017. ECOLI[S]². Essays and notes on ecolinguistic synergy and synthesis. Poznań: Katedra Ekokomunikacji UAM.

Quine, W.V.O. 1969. "Epistemology naturalized". In: Quine, W.V.O. Ontological relativity and other essays. New York: Columbia University Press. 69-90.

Schwitzgebel, E. 2015. "Belief". In: Stanford Encyclopedia of philosophy. Accessed July 2015. http://plato.stanford.edu/entries/belief/\#Bib

Sellars, W. 1963. "Empiricism and the philosophy of mind". In: Sellars, W. Science, Perception and Reality. Atascadero, CA: Ridgeview Publishing Co. 127-196.

Sosa, E. 1991 [1980]. "The raft and the pyramid: coherence versus foundations in the theory of knowledge". Midwest Studies in Philosophy 5. 3-25. Reprinted in: Sosa, E. (ed.). Knowledge in Perspective. Cambridge: Cambridge University Press. 165-191.

Sosa, E. 2003. "Beyond internal foundations to external virtues". In: BonJour, L. and E. Sosa. (eds.). Epistemic justification: internalism vs. externalism, foundations vs. virtues. Malden, Mass.: Blackwell. 97-170.

Sun J. 1993. "Evidentials in Amdo Tibetan". Bulletin of the Institute of History and Philology 63.4. 945-1001.

Tournadre, N. 2008. "Arguments against the concept of 'conjunct'/'disjunct' in Tibetan". In: Huber, B. and M. Volkart and P. Wildmer. (eds.). Chomolangma, Demawend und Kasbek: Festschrift für Roland Bielmeier zu seinem 65. Geburtstag. Halle: IITBS. 281-308. 
Weber, D.J. 1986. "Information, perspective, profile and patterns in Quechua". In: Chafe, W. and J. Nichols. (eds.). Evidentiality: the linguistic coding of epistemology. Norwood, N.J.: Ablex Publishing Corporation. 137-155.

Weber, D.J. 1989. A Grammar of Huallaga (Hиánuco) Quechua. Berkeley, Los Angeles, London: University of California Press.

Willett, T. 1988. "A cross-linguistic survey of the grammaticalization of evidentiality". Studies in Language 12. 51-97.

Whorf, B.L. 1956. Language, thought and reality. Selected writings by Benjamin Lee Whorf. Ed. by J.B. Carroll. Cambridge, Mass.: MIT Press.

Woleński, J. 2005. Epistemologia. Poznanie, prawda, wiedza, realizm. Warszawa: Wydawnictwo Naukowe PWN.

Woodbury, A.C. 1986. "Interactions of tense and evidentiality: A study of Sherpa and English". In: Chafe, W. and J. Nichols. (eds.). Evidentiality: The Linguistic coding of epistemology. Norwood, N.J.: Ablex Publishing Corporation. 188-202.

Zagzebski, T.L. 1996. Virtues of the mind. An inquiry into the nature of virtue and the ethical foundations of knowledge. Cambridge: Cambridge University Press.

Ziemińska, R. 2013. Historia sceptycyzmu. Toruń: Wydawnictwo Naukowe Uniwersytetu Mikołaja Kopernika. 